\title{
Employment prospects and trends for gastroenterology trainees in Canada: A nationwide survey
}

\author{
Roshan Razik MD¹, Maria Cino MD MSc FRCPC ${ }^{1}$, \\ the Canadian Gastroenterology Program Directors ${ }^{2}$, Geoffrey C Nguyen MD PhD FRCPC ${ }^{1}$
}

R Razik, M Cino, the Canadian Gastroenterology Program Directors, GC Nguyen. Employment prospects and trends for gastroenterology trainees in Canada: A nationwide survey. Can J Gastroenterol 2013;27(11):647-652.

BACKGROUND: Many gastroenterology (GI) trainees face a variety of barriers to stable employment and are finding it increasingly difficult to secure employment in their chosen field.

OBJECTIVE: To elucidate factors that contribute to the burden of unemployment and underemployment, and to examine solutions that may remedy this growing problem in the field of GI.

METHODS: A nationwide survey of current, incoming and recently graduated individuals of GI training programs in Canada was conducted. Trainees in pediatric GI programs and those enrolled in subspecialty programs within GI were also included.

RESULTS: The response rate was $62 \%$, with $93 \%$ of respondents enrolled in an adult GI training program. Many (73\%) respondents planned to pursue further subspecialty training and the majority (53\%) reported concerns regarding job security after graduation as contributory factors. Only $35 \%$ of respondents were confident that they would secure employment within six months of completing their training. Regarding barriers to employment, the most cited perceived reasons were lack of funding (both from hospitals and provincial governments) and senior physicians who continue to practice beyond retirement years. Sixty-nine per cent perceived a greater need for career guidance and $49 \%$ believed there were too many GI trainees relative to the current job market in their area. Most residents had a contingency plan if they remained unemployed $>18$ months, which often included moving to another province or to the United States.

CONCLUSION: GI trainees throughout Canada reported substantial concerns about securing employment, citing national retirement trends and lack of funding as primary barriers to employment. Although these issues are not easily modifiable, certain problems should be targeted including optimizing training quotas, tailoring career guidance to the needs of the population, and emphasizing credentialing and quality control in endoscopy.

Key Words: Education; Employment; Gastroenterology; Jobs; Residency training

Gastroenterology (GI) trainees in Canada are eligible for independJent practice after completing an average of three years of internal medicine and an additional two years of GI training. This is true for many of the specialty branches of internal medicine. However, unlike some medical specialties, in which procedures are not a part of routine practice, newly minted GI physicians are finding it increasingly difficult to secure stable work.

The past decade has witnessed an extraordinary rise in the demand for GI services across Canada; there are many reasons for this trend. Over time, provincial ministries of health have recognized the

\section{Les perspectives et les tendances de l'emploi pour les stagiaires en gastroentérologie au Canada : une enquête nationale}

HISTORIQUE : De nombreux stagiaires en gastroentérologie (GI) affrontent divers obstacles à un emploi stable et trouvent de plus en plus difficile de décrocher un emploi dans le domaine de leur choix.

OBJECTIF : Déterminer les facteurs qui contribuent au fardeau du chômage et du sous-emploi et chercher des solutions pour remédier à ce problème croissant en GI.

MÉTHODOLOGIE : Les chercheurs ont mené une enquête nationale auprès des nouveaux, prochains et récents diplômés de programmes de formation en GI au Canada. Les stagiaires au sein des programmes de GI pédiatrique et ceux inscrits dans un programme de surspécialité de la GI y ont également participé.

RÉSULTATS : Le taux de réponse s'est élevé à $62 \%, 93 \%$ des répondants participant à un programme de formation en GI pour adultes. De nombreux répondants ( $73 \%$ ) prévoyaient suivre une formation en surspécialité, et la majorité (53\%) précisaient que leurs craintes à l'égard de la sécurité d'emploi après l'obtention de leur diplôme contribuaient à cette décision. Seulement $35 \%$ des répondants étaient convaincus de trouver un emploi dans les six mois suivant leur formation. Pour ce qui est des obstacles à l'emploi, les raisons perçues les plus citées étaient le manque de financement (tant de la part des hôpitaux que des gouvernements provinciaux) et les médecins chevronnés qui continuent de travailler après l'âge de la retraite. Soixante-neuf pour cent percevaient avoir un plus grand besoin d'orientation de carrière et $49 \%$ pensaient qu'il y avait trop de stagiaires en GI par rapport au marché de l'emploi dans leur région. La plupart des résidents s'étaient dotés d'un plan B s'ils demeuraient sans emploi plus de 18 mois, lequel incluait souvent un déménagement dans une autre province ou aux États-Unis.

CONCLUSION : Les stagiaires en GI du Canada ont confié avoir de grandes inquiétudes quant à l'obtention d'un emploi, citant les tendances nationales en matière de départ à la retraite et le manque de financement comme les principaux obstacles à l'emploi. Même si ces problèmes ne sont pas faciles à modifier, il faudrait en cibler certains, y compris l'optimisation des quotas de formation, l'adaptation de l'orientation de carrière aux besoins de la population et l'insistance sur les titres de compétence et le contrôle de la qualité en endoscopie.

${ }^{1}$ Division of Gastroenterology, Department of Medicine, University of Toronto, Toronto, Ontario; ${ }^{2}$ See Acknowledgements

Correspondence: Dr Geoffrey C Nguyen, Department of Medicine, University of Toronto, 600 University Avenue, Suite 437, Toronto, Ontario M5G 1 X5.

Telephone 416-586-4800 ext 2819, fax 416-586-5971, e-mail geoff.nguyen@utoronto.ca

Received for publication July 28, 2013. Accepted September 16, 2013 


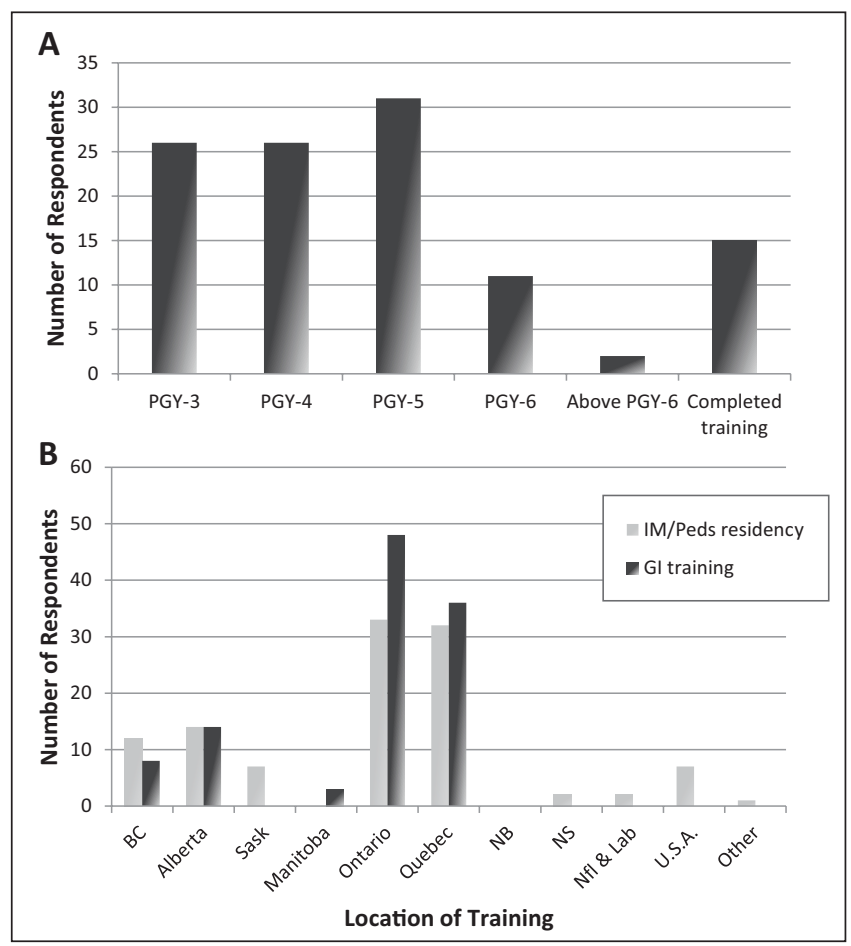

Figure 1) A Distribution of respondents according to postgraduate year (PGY) level of training. B Distribution of respondents according to location of core training (internal medicine [IM] or pediatrics [Peds]) and gastroenterology (GI) training. BC British Columbia; NB New Bruswick; NS Nova Scotia; NFl Ë Lab Newfoundland and Labrador; Sask Saskatchewan

Canada has led to an increased prevalence of viral hepatitis, which in turn has engendered a growing demand for hepatology services, especially in the country's major cities.

Despite this increased demand for GI services, new graduates are facing an unprecedented dearth of full-time or even part-time positions. Many in the field have recognized this problem for years but the specific barriers facing young GI trainees have yet to be fully explored. The present nationwide survey-based study sought to gauge the opinions of current trainees, recent graduates and incoming trainees on the employment prospects within their specialty. We sought to elucidate factors that contribute to the burden of unemployment and underemployment, and examined solutions that may remedy this growing problem in the field of GI.

\section{METHODS}

An online survey was developed using the commercially available survey provider 'NoviSurvey'. Questions were constructed to elicit trainee views on current GI employment prospects in Canada. The survey was vetted among a group of adjudicators to ensure clarity of intent and avoid confusion in interpretation.

Resident physicians currently enrolled in GI training programs at medical schools across Canada were contacted via individualized e-mails and invited to participate in the survey. Additionally, incoming GI trainees (usually residents in their third year of internal medicine or pediatrics training) and recent graduates (those who completed their GI training within the preceding 12 months) were also invited to participate. Finally, trainees in pediatric GI programs, those enrolled in subspecialty programs and those in francophone universities were also included.

Using the assistance of GI program directors from across the country, a database of e-mail addresses was generated for the aforementioned trainees. Each participant received an individualized survey link directly from the principal investigator (GCN). The invitation e-mail offered respondents the opportunity to electronically provide consent or decline participating in the survey. After the initial invitation

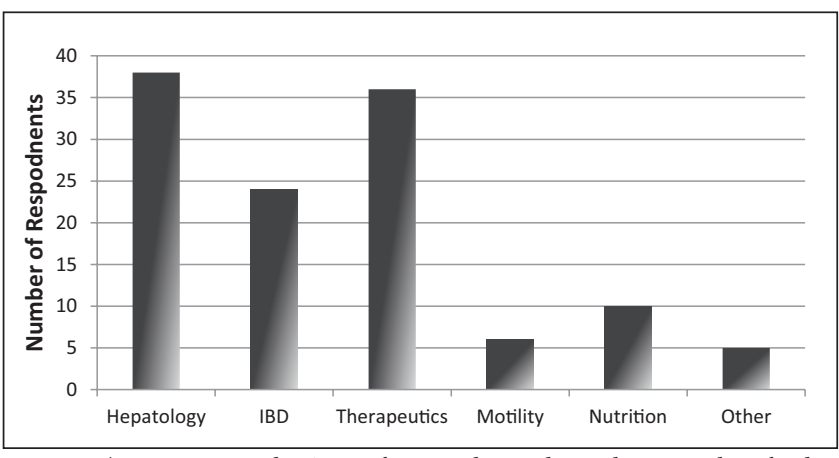

Figure 2) Approximately $72 \%$ of respondents planned to complete further subspecialty training. Respondents were allowed to choose one or more broad categories as their area of focus. Under 'Other', answers included Applied Microbiome, Clinical Epidemiology and GI Oncology. IBD Inflammatory bowel disease

e-mail, nonresponders were sent up to two more reminder e-mails inviting them to participate. The entire study was conducted in English.

The survey contained multiple-choice questions, ranking questions, Likert scales and free-text fields. Data were collected in an anonymous fashion, with responses coded using randomly generated unique identifiers. Stata version 10 (StataCorp, USA) was used to conduct descriptive analyses. The $\chi^{2}$ test or Fisher's exact test was used to compare categorical variables while the Student's unpaired $t$ test was used to compare continuous variables.

The study protocol received approval from the Research Ethics Board at Mount Sinai Hospital (a member of the Toronto Academic Health Sciences Network, Toronto, Ontario).

\section{RESULTS}

After enrollment was completed and invalid e-mail addresses were omitted, a total of 181 physicians affiliated with 12 medical schools across Canada were invited to participate; one institution declined involvement in the survey. Of those invited, 111 responded $(62 \%$ response rate), of whom 49 were female. The majority (50\%) were between 25 and 35 years of age.

\section{Quantitative results}

The distribution of trainees according to postgraduate year level is shown in Figure 1A. Approximately $7.2 \%$ of the respondents were registered in a pediatric GI training program, but given the small pool of pediatric trainees, the response rate was actually $67 \%$. The majority (59\%) of trainees had completed their internal medicine training in Ontario or Quebec, and almost one-third came from western or central Canada (Figure 1B), with a similar geographical distribution noted for location of GI training (Figure 1B).

Almost three-quarters of respondents stated that they planned to pursue further subspecialty training, with many citing therapeutic endoscopy and hepatology as future career goals (Figure 2). The majority $(53 \%)$ of these trainees chose to pursue advanced training based on concerns about job security after graduation. In terms of their ideal setting, $44 \%$ desired a primarily academic practice while 39\% were interested in a community practice with academic affiliation. As for their ideal practice environment, the vast majority (81\%) sought an urban centre, with $31 \%$ reporting interest in a suburban centre. Only $7 \%$ of trainees desired to work predominantly in the community and none wanted to work in a rural area. Female respondents were nearly twice as likely to prefer working in a primarily academic setting compared with their male counterparts (61\% versus $32 \%$, respectively; $\mathrm{P}=0.02)$. Pediatric GI trainees were more likely than adult GI trainees to pursue a primarily academic practice $(100 \%$ versus $40 \%$, respectively; $\mathrm{P}=0.02$ ).

Approximately $35 \%$ of trainees were confident they would secure a job in their preferred subspecialty field, setting and location; this sense 
of confidence was more common among individuals training in Quebec compared with other provinces (48\% versus 29\%, respectively; $\mathrm{P}=0.01)$. The vast majority $(78 \%)$ of trainees were anxious about securing a job, although employment-related anxiety also varied according to region. Trainees from Quebec were less likely to report anxiety over employment than their counterparts from western and central Canada (56\% versus 91\%, respectively; $\mathrm{P}=0.04$ ) and Ontario ( $56 \%$ versus $87 \%$, respectively; $\mathrm{P}=0.03$ ). Pediatric trainees were similar to their adult GI counterparts with regard to their confidence in securing employment (38\% versus $35 \%$, respectively; $\mathrm{P}=0.84$ ) and willingness to relocate for employment ( $50 \%$ versus $41 \%$, respectively; $\mathrm{P}=0.44)$.

Overall, $42 \%$ of GI trainees were amenable to relocating to a less desirable location. Those training in Quebec were, however, less agreeable to moving to a less preferable practice area than their counterparts from other parts of the country (36\% versus $44 \%$, respectively; $\mathrm{P}=0.003$ ). Only $18 \%$ were willing to practice general internal medicine in the event they were not able to find a job in their chosen subspecialty. GI trainees in Quebec were much less inclined to practice general internal medicine than non-Quebec trainees $(3 \%$ versus $25 \% ; \mathrm{P}<0.0001$ ).

Approximately one-half of trainees had a contingency plan in the event they remained unemployed $>18$ months after completing their training. Of those who did have a back-up plan, approximately $36 \%$ would search for jobs in another part of the province or, more often, in another province entirely (Figure 3). Almost one-third (31\%) would pursue further fellowship training, while $43 \%$ would seek employment in the United States (US). Only $4.2 \%$ were open to retraining in another medical residency.

Nearly one-half (49\%) of GI trainees believed that there were too many residents being trained in GI relative to their local job market, and this perception was consistent throughout all regions of the country. On the other hand, a minority (38\%) of pediatric GI trainees believed that there was a surplus of pediatric GI trainees being trained locally. Table 1 summarizes the sentiments of respondents with regard to a variety of factors related to employment in Canada.

The most highly ranked potential barriers to employment perceived by residents were lack of funding from both hospitals and the provincial government, and extended duration of clinical practice among senior gastroenterologists well past the traditional retirement years (Figure 4). At the other end of the scale, respondents reported "overall decline in need for gastroenterology services" and "need for further sub-specialty training" as the least important barriers to employment. Despite these barriers, only $5 \%$ expressed regret for selecting a career in GI. Trainees from Quebec were more satisfied with their career choice, with no responders expressing regret compared with $7.4 \%$ in the rest the country. A slightly greater minority of pediatric trainees regretted their career choice in GI compared with adult trainees, although this was not statistically significant $(13 \%$ versus $4 \% ; \mathrm{P}=0.5)$. For pediatric trainees, the

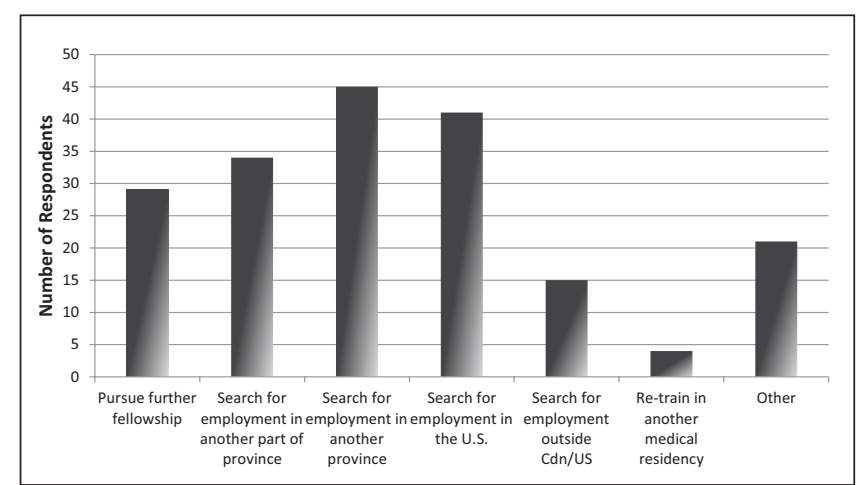

Figure 3) Respondents were asked about their contingency plan should they remain unemployed $>18$ months after completing their training

most significant hurdle to employment was reported to be senior physicians practicing past the traditional retirement age. Similar to their adult GI colleagues, they also cited a declining need for GI services as the least important variable.

Most trainees (69\%) desired more career guidance. For physicians potentially interested in a research career, most cited a difficulty in obtaining research funding, low financial remuneration and additional years of training required as potential barriers. Approximately two-thirds of respondents were considering a career in research at the time of the survey, and most (69\%) believed that the optimal ratio of clinical to research responsibilities would be $75 \%$ clinical and $25 \%$ research.

\section{Qualitative results}

Trainees were provided with the opportunity to leave written comments at various stages of the survey. A variety of concerns were brought forward and these could be crystallized into three broad themes: the issue of surgeons performing a disproportionate number of endoscopies; concerns surrounding the hiring of non-Royal College of Physicians and Surgeons of Canada (RCPSC)-certified physicians or non-Canadian physicians; and the complex quota allocations that decide the future of Quebec trainees.

Many respondents were quick to mention the issue of general surgeons with busy endoscopy practices. Some stated they were concerned about "surgeons performing the duties of a gastroenterologist". Others pointed out the lack of quality control markers and that cecal intubation rates may vary widely between surgeons and gastroenterologists. A related issue was the problem of limited endoscopy time and the concern that "endo time is controlled by the people using it rather than a central administration".

The pediatric GI trainees often raised the issue of non-RCPSCcertified physicians being preferentially recruited, especially in academic centres:

\section{TABLE 1}

Respondents' views on employment prospects in gastroenterology (GI) in Canada

\begin{tabular}{|c|c|c|c|c|c|}
\hline View & $\begin{array}{l}\text { Strongly } \\
\text { agree }\end{array}$ & Agree & Neutral & Disagree & $\begin{array}{l}\text { Strongly } \\
\text { disagree }\end{array}$ \\
\hline I feel anxious about securing a job & $36(35.6)$ & $42(41.6)$ & $12(11.9)$ & $3(3.0)$ & $7(6.9)$ \\
\hline I am likely to pursue a fellowship outside Canada & $30(29.7)$ & $21(20.8)$ & $21(20.8)$ & $18(17.8)$ & $11(10.9)$ \\
\hline I am willing to practice general internal medicine as an alternative & $2(2.0)$ & $16(15.8)$ & $20(19.8)$ & $32(31.7)$ & $31(30.7)$ \\
\hline $\begin{array}{l}\text { There are too many residents being trained in GI in my location } \\
\text { relative to the current job market for GI specialists }\end{array}$ & $20(19.8)$ & $29(28.7)$ & $36(35.6)$ & $15(14.9)$ & $1(1.0)$ \\
\hline I had a mentor for career guidance during my training & $14(13.9)$ & $32(31.7)$ & $25(24.8)$ & $21(20.8)$ & $9(8.9)$ \\
\hline I would like more career guidance & $28(27.7)$ & $42(41.6)$ & $23(22.8)$ & $5(5.0)$ & $3(3.0)$ \\
\hline I regret choosing GI as a career choice & $0(0)$ & $5(5.0)$ & $13(12.9)$ & $31(30.7)$ & $52(51.5)$ \\
\hline I am willing to move to a less preferred practice location & $1(1.0)$ & $41(40.6)$ & $26(25.7)$ & $22(21.8)$ & $11(10.9)$ \\
\hline $\begin{array}{l}\text { Within six months of completing my training, I am confident I will secure } \\
\text { a job in my chosen practice environment and setting in my chosen } \\
\text { area of subspecialty interest }\end{array}$ & $14(13.9)$ & $22(21.8)$ & $20(19.8)$ & $27(26.7)$ & $19(18.8)$ \\
\hline
\end{tabular}

Data presented as $n$ (\%). Answers were provided on a Likert scale 


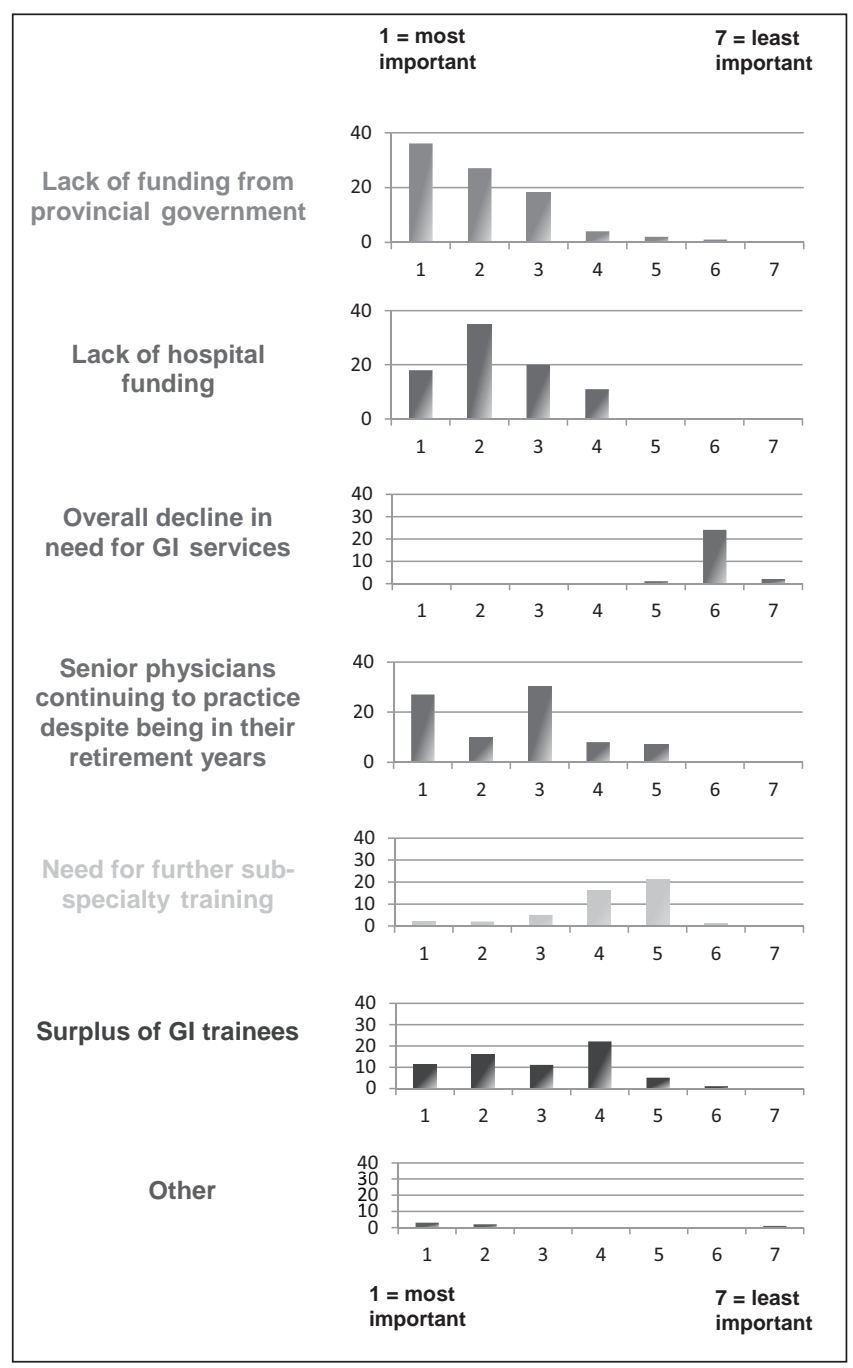

Figure 4) Respondents were asked to rank a list of variables as potential barriers to employment as a gastroenterologist. Factors believed to be unimportant were not ranked. Under 'Other', themes included limited access to finite resources, the perceived excess number of surgeons performing endoscopy and the perceived number of foreign trainees securing jobs. GI Gastroenterology

The last three people hired by my GI Division have no Royal College certification, foreign grads who came for Fellowship transiently and stayed. I wish to stay in Canada. My education has been partially subsidized by taxpayers like myself and my family. I want to give back to MY community. I don't want to keep doing GI training and working in the states while waiting for a job to open in Canada.

This sentiment was echoed by others:

...when I was near the end of my second year, there were 4-5 job opportunities. I started applying for positions. However, I ... took a year off. During that year off, most of those spots were filled, 3 by non-Canadian graduates.

Finally, Quebec residents identified the government-legislated quota allocation system as being somewhat obstructive to their quest to procure stable employment:

The main issue is that the government limits the number of positions in each center, irrelevant of the actual need.

Still others pointed out the relative competitiveness:

I am luckier than most in that I was guaranteed a PREM prior to starting my masters. I also feel that I had to fight very hard...
Other comments left by respondents:

I didn't feel as if I had much support or guidance from my mentors, although I'm not sure what they could have done either since they can't create jobs where there are none.

Great prospects in USA but poor in Canada.

I find that those who have niche skills are holding them close and continuing to practice without participating in call far into retirement age, thus limiting job prospects.

There are jobs out there - they just are not posted on jobs.com. In the end, academic centres will suffer the most since they will be losing potential academic clinicians (to) community hospitals.

It was the most stressful experience of my life, going through my R5 year in GI without there being any job prospects on the horizons.

\section{DISCUSSION}

Physician unemployment and underemployment has become a disturbing trend in many areas of medicine, particularly in the more resource-intensive specialties. GI, with its reliance on endoscopy suites, specialized equipment, trained personnel and periprocedural acute care facilities, is no stranger to this phenomenon. However, with a rapidly rising demand for GI services in Canada, it remains unclear why young GI physicians are experiencing considerable difficulty securing stable employment. The present study sheds light on some of these issues, at least from the trainees' perspective.

With an aging population and increasing influx of immigrant groups, demand for GI services is higher in Canada than ever before. Importantly, wait times to see a digestive disease specialist have been less than optimal in the recent past (3). A few years ago, the Canadian Association of Gastroenterology set out to define target wait times for a variety of gastrointestinal diseases (4). Referrals for common luminal and hepatobiliary problems were assessed and consensus guidelines were compiled by an expert panel. Shortly after these recommendations were published, Yu et al (3) showed that almost $80 \%$ of patients awaiting consultation did not meet these targets and that number was closer to $90 \%$ for screening colonoscopy. This was later confirmed by self-reported wait times being too long or "far too long" in $>40 \%$ of cases (5). With such discrepancies between consensus recommendations and actual wait times, it is clear that there is no shortage of demand for GI services. Furthermore, the supply of GI physicians - to use the economic term 'inventory' - is similarly well stocked, if not somewhat understocked. What is required is a framework for matching this meagre supply to the growing demand to improve, or at least maintain, the health of all Canadians.

Government funding may play a pivotal role in this disequilibrium. In our study, $>80 \%$ of respondents identified a lack of funding from the provincial government as one of the top three barriers to employment. Seventy-two per cent of trainees reported the same about a lack of hospital funding. In Ontario, the Health and Human Resources branch of the Ministry of Health tracks the number of GI positions year-to-year in the province (6). In the two-year period between 2004 and 2006, the number of GI training positions increased by $79 \%$. However, the number of full-time employment opportunities has not matched that upward trend. More recently, the number of GI training positions offered has plateaued - or even contracted - in some programs (7). This is perhaps in response to the limited employment prospects for new graduating GI physicians. Respondents in our study perceived that a surplus of GI trainees was not the major issue, ranking it fourth on a six-item list of potential barriers.

Many participants in our study left rather lengthy written comments, sometimes several paragraphs in length, reflecting both the importance of such issues and the urgency. During our qualitative analysis, a number of themes became clear. First, trainees believed that a significant issue was that of endoscopy time being occupied by surgeons. In fact, this has been corroborated in the literature, with Hilsden et al (8) showing that the absolute number of surgeon endoscopists was higher than 
the number of GI doctors performing endoscopy in Canada. This was especially true in suburban and rural areas of the country. In addition to maintaining their operative practice, many surgeons are actively engaged in endoscopy given its higher turnover compared with standard surgical practice. Many respondents expressed concern that both surgeons and gastroenterologists have to share time in the endoscopy suite - a scarce resource that is critical to the practice of each specialist. A related issue is that endoscopy time is often controlled by physicians who perform endoscopy and not by a central administration. One way to potentially have more equitable access to this finite resource is to move scheduling to an independent body. This would also serve the public, given that quality and completeness of endoscopic examination may be related to the training of the operator. For example, early repeat colonoscopy after an index examination is a surrogate measure of endoscopy quality (9) and studies have shown that the rate of early repeat colonoscopy is higher among nongastroenterologist endoscopists. Similarly, Baxter et al (10) showed that the rate of postcolonoscopy colorectal cancer was higher among certain endoscopists (nongastroenterologists and nongeneral surgeons) and in certain settings (nonhospital-based endoscopy units).

Another common theme highlighted was the issue of senior physicians who continue to be clinically active well past the traditional retirement age. Approximately two-thirds of participants listed this among the top three barriers to stable employment as a gastroenterologist. They further went on to note the less stringent expectations that hospital administrations mandate for their more senior gastroenterologists with regard to participation in the hospital's call pool. This should not be interpreted as a call for mandatory retirement nor is it ageism in action. Rather, physicians in all stages of their training should be cognizant of this observation and be receptive to sharing the scarce resource of endoscopy time with younger colleagues.

Many GI trainees also pointed to the practice of hiring physicians who did not hold certification with the RCPSC or non-Canadian doctors over those trained in Canada. This trend appeared to be more common among the pediatric GI programs. In fact, Morinville et al (11) identified this as a problem several years ago and showed that nearly two-thirds of the pediatric GI trainees enrolled came from outside of Canada. More importantly, only one-third of the physicians who were trained in Canada actually entered the Canadian workforce, with the majority of these physicians leaving the country to practice elsewhere. It would appear intuitive that trainees entering the workforce are disproportionately hailing from Canadian backgrounds; our survey respondents would, however, disagree. Why such a discrepancy exists is unclear but this is an issue that requires further exploration.

Respondents also mentioned potential alternatives should they remain unemployed after completion of their training. Some stated that they would retrain in specialties with higher demand such as geriatrics or generalist fields such as family medicine or general internal medicine. Others were interested in changing their practice location, with almost one-half the participants interested in moving to the US for work. Population data show that compared with Canada, there are approximately double the number of gastroenterologists per 100,000 of the population currently working in the US (12). This ratio of gastroenterologists to population is also higher in other developed countries such as France and Australia. Despite having a much higher proportion of employed GI physicians, the US is predicting a massive void of unfilled positions, with numbers as high as 90,000 vacant jobs in a variety of specialties $(13,14)$.

In the present study, GI trainees in Quebec identified other issues unique to their province. They frequently mentioned restrictive programs, such as the Physician Resource Plan (PREM), as a barrier to stable employment. These government-mandated limits on the number of positions were regarded as obstructive and inflexible by many trainees. However, some trainees also praised the system, stating that this arrangement allowed for more structured and equitable access to care for the general public. In general, Quebec trainees reported lower anxiety levels with regard to finding employment. They were also more confident in obtaining a position in their chosen specialty and practice location, and this was reflected in their relative reluctance to relocate for work or to practice general internal medicine as an alternative. In Quebec, the government dictates the number of positions in various medical specialties based on the needs of various institutions. This may be one reason why Quebec respondents did not have the same apprehension with regard to their job prospects.

Many of the factors listed here are not easily modifiable nor are they problems that can be resolved in the short term. However, certain issues can be tackled, and we believe the responsibility lies with a variety of national and provincial stakeholders to initiate the process. For example, transitioning GI trainees into full-time jobs should receive the full support from every provincial GI society and certainly every training program. This may be facilitated by liaising with hospital administrators in academic and community settings and fostering recruitment programs for their trainees. Additionally, the Canadian Association of Gastroenterology, as well as various provincial GI bodies, should be motivated to work together to take leadership in this area. One key area of concern is that of quality endoscopy. Efforts should be made to improve credentialing in endoscopy, to emphasize quality control and to make these data available to key stakeholders, including the public. A separate issue that was distilled from our results is that trainees would prefer to not work in rural communities. The provincial health ministries should spearhead initiatives to make these vacancies more attractive to trainees, either through incentive programs or by relocating certain training centres to satellite campuses to enable interested trainees to experience rural medicine.

Moreover, GI training programs should attempt to provide more structured guidance and mentorship, again targeting eventual employment as the primary goal. Early and frank discussions with trainees regarding the employment climate should be encouraged, and customizing training to suit real-world needs should be made a priority. Similarly, the preconceived notion of finding work in a hospital setting immediately after graduation should be adjusted. With changes in funding programs and government-mandated restructuring, endoscopy services are increasingly being moved out of acute care facilities and into stand-alone endoscopy practices. GI trainees must adjust their expectations with this in mind. Second, the issue of number of training positions offered should also be scrutinized. One way to determine this number, as has often been the case, is to consider the amount of funding allotted and compare that with the number of individuals needed to fill the call schedule. Although these factors are important, governments and training programs should also acknowledge that when they accept an internal medicine or pediatrics resident into their programs, they should be training them to not only be fully qualified gastroenterologists but also gainfully employed gastroenterologists.

To our knowledge, the present study was the first of its kind to examine GI employment prospects on a national level with input from those that are most affected. In future research, we aim to study other important stakeholders, such as GI program directors, hospital administrators and provincial ministries of health, to gauge what they believe are potential barriers to employment.

\section{CONCLUSION}

Securing stable employment in the field of GI is a well-recognized problem among educators, ministries of health and, most of all, GI trainees. Unfortunately, none of these groups have been able to alleviate the trend to date. Respondents in the present study identified a lack of funding and national retirement trends as primary reasons for this growing phenomenon. Many of these issues are not easily remedied but certain modifiable factors do exist. The provincial GI societies, various health ministries and GI training programs may be able to ameliorate some of these concerns by optimizing the number of gastroenterologists being trained, spearheading policies that enhance quality endoscopy and providing more focused career guidance to help GI trainees secure jobs. 


\section{CANADIAN GASTROENTEROLOGY PROGRAM}

DIRECTORS: Collin Barker, University of British Columbia; Annie Beaudoin, Université de Sherbrooke; Mickael Bouin, Université de Montréal; Herbert Brill, McMaster University; Michael Cantor, University of Manitoba; Nilesh Chande, Western University; Nazira Chatur, University of British Columbia; Shane Devlin, University of Calgary; Réjean Dubé, Université Laval; Christophe Faure, Université de Montréal; Lawrence Hookey, Queen's University; Adriana Lazarescu, University of Alberta; Simon Ling, University of Toronto; Leanna McKenzie, University of Calgary; Veronique D. Morinville, McGill University; Rabindranath Persad, University of Alberta; Navaaz Saloojee, University of Ottawa; Frances Tse, McMaster University; Philip Wong, McGill University.

DISCLOSURES: The authors have no finacial disclosures or conflicts of interest to declare.

\section{REFERENCES}

1. Cancer Care Ontario. <www.cancercare.on.ca/pcs/screening/ coloscreening/ (Accessed June 29, 2013).

2. Rocchi A, Benchimol EI, Bernstein CN, et al. Inflammatory bowel disease: A Canadian burden of illness review. Can J Gastroenterol 2012;26:811-7.

3. Yu D, Hopman WM, Paterson WG. Wait time for endoscopic evaluation at a Canadian tertiary care centre: Comparison with Canadian Association of Gastroenterology targets. Can J Gastroenterol 2008;22:621-6.

4. Paterson WG, Depew WT, Pare P, et al. Canadian consensus on medically acceptable wait times for digestive health care. Can J Gastroenterol 2006;20:411-23.
5. Paterson WG, Barkun AN, Hopman WM, et al. Wait times for gastroenterology consultation in Canada: The patient's perspective. Can J Gastroenterol 2010;24:28-32.

6. Goodyear J, Adams PC. Allocation of gastroenterology training positions in Ontario: Supply or demand? Can J Gastroenterol 2009;23:82-3.

7. Canadian Residency Matching Service. <www.carms.ca/program MSM_2/program_en.jsp?path=default_en.jsp\&p=16>. (Accessed June 26, 2013).

8. Hilsden RJ, Tepper J, Moayyedi P, Rabeneck L. Who provides gastrointestinal endoscopy in Canada? Can J Gastroenterol 2007;21:843-6.

9. Ko CW, Dominitz JA, Green P, Kreuter W, Baldwin LM. Utilization and predictors of early repeat colonoscopy in Medicare beneficiaries. Am J Gastroenterol 2010;105:2670-9.

10. Baxter NN, Sutradhar R, Forbes SS, et al. Analysis of administrative data finds endoscopist quality measures associated with postcolonoscopy colorectal cancer. Gastroenterology 2011;140:65-72.

11. Morinville V, Drouin E, Levesque D, et al. Canadian pediatric gastroenterology workforce: Current status, concerns and future projections. Can J Gastroenterol 2007;21:653-64.

12. Moayyedi P, Tepper J, Hilsden R, Rabeneck L. International comparisons of manpower in gastroenterology. Am J Gastroenterol 2007;102:478-81.

13. Dill MJ, Salsberg ES. The complexities of physician supply and demand: Projections through 2025. Center for Workforce Studies. AAMC, November 2008.

14. Kralj B, Marusic G. OHIP funding cuts threaten physician supply. Ontario Med Rev 2012:16-9. 


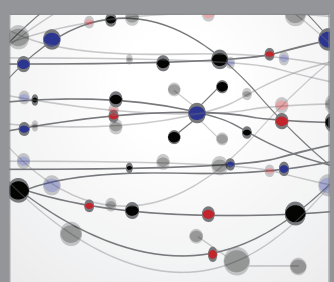

The Scientific World Journal
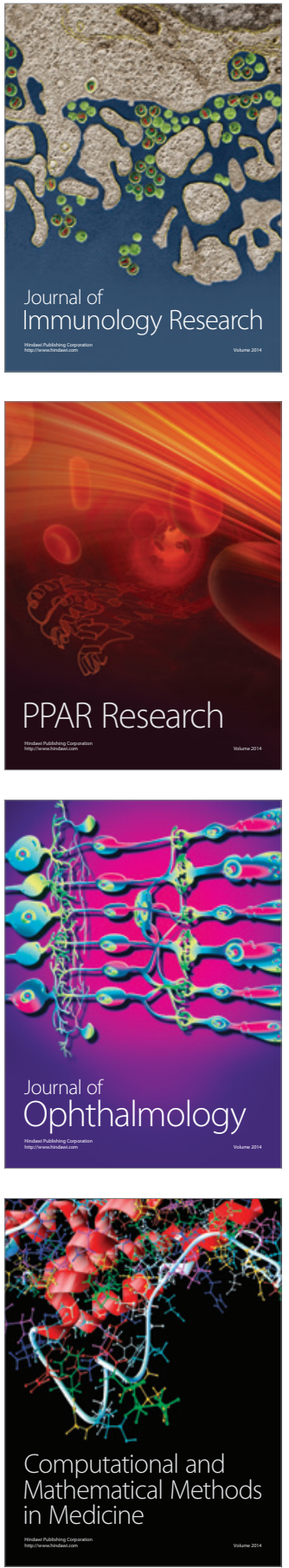

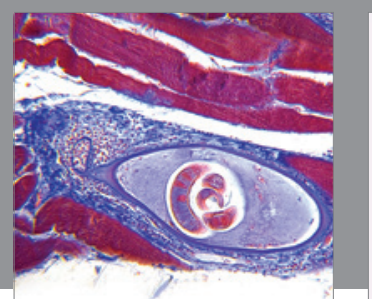

Gastroenterology Research and Practice

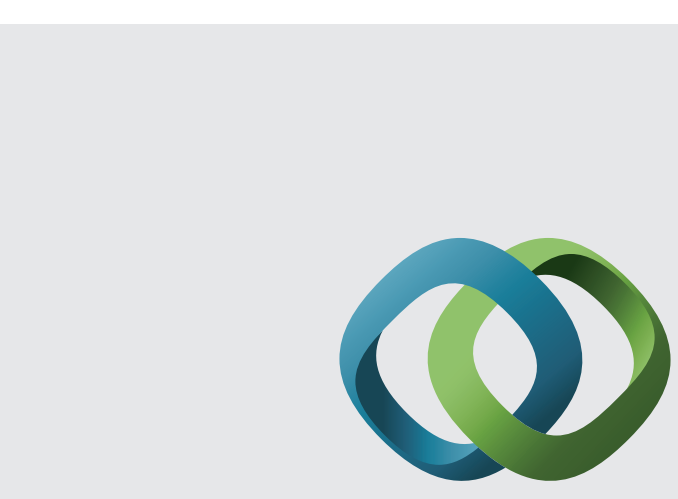

\section{Hindawi}

Submit your manuscripts at

http://www.hindawi.com
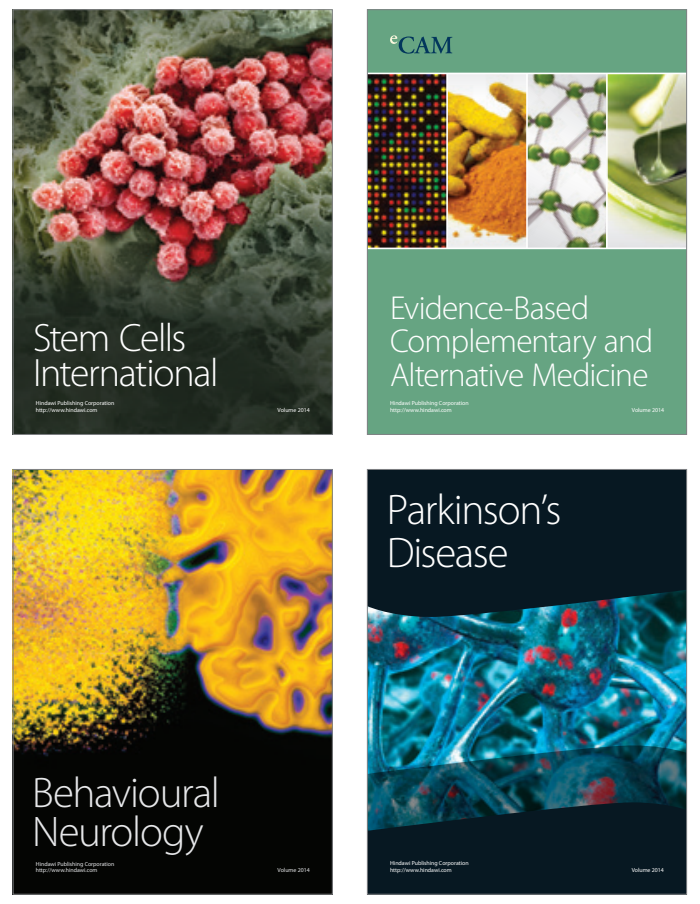
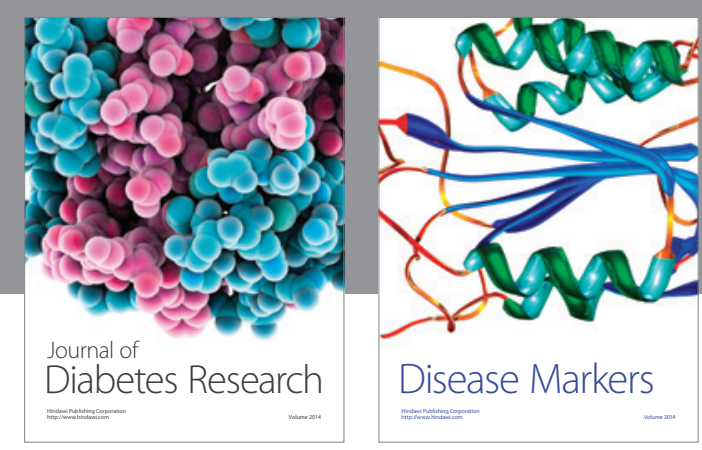

Disease Markers
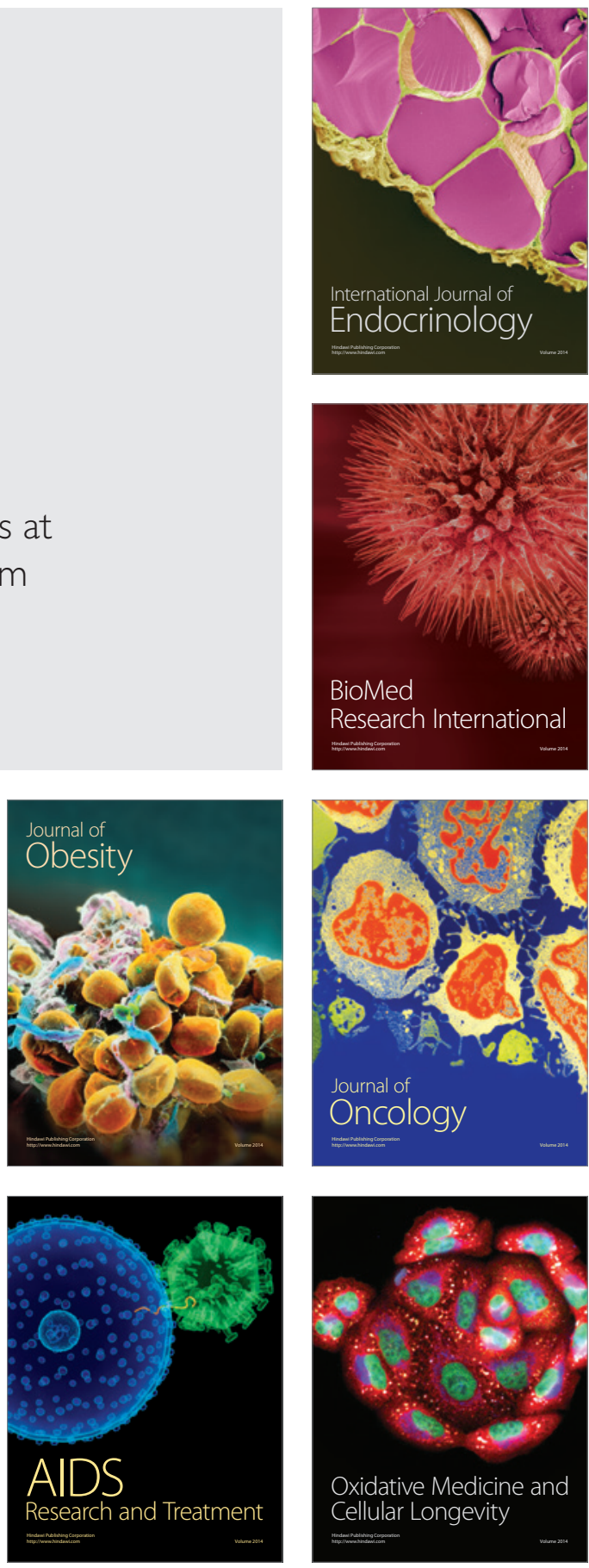